\title{
Padrões florísticos do componente arbóreo sob interferência de trilhas em um trecho de Floresta Ombrófila Densa de Transição em São Paulo, SP, Brasil ${ }^{1}$
}

Juliana Kiomi Rodrigues Hirata ${ }^{2,4}$, Maria Margarida da Rocha Fiuza de Melo ${ }^{2,4}$ e Pedro Vasconcellos Eisenlohr²,3

Recebido: 09.11.2009; aceito: 05.08.2010

\begin{abstract}
Floristic patterns of the tree community under the influence of trails in a Transition Rainforest area, Sao Paulo, SP, Brazil). Trails can modify the floristic composition of a given location, since some environmental conditions are visibly different from the unvisited forest area. The central hypothesis was that trails could be related to variations in species composition, leading to the constitution of floristic blocks, each of them formed by plots of a defined interference degree. Thirty $2 \times 50 \mathrm{~m}$ plots were sampled in the Parque Estadual das Fontes do Ipiranga, city of Sao Paulo, State of Sao Paulo, Brazil, of which, 10 next to a wide and intensively visited trail, 10 next to a narrow and rarely visited trail, and 10 next to a relatively preserved area. All trees and palms $(\mathrm{DBH} \geq 2.5 \mathrm{~cm}$ ) were sampled. Cluster (by UPGMA), ordination (by CA and DCA) and TWINSPAN analyses indicated floristic distinction between the three sectors. As the floristic composition varied by level of use and width of the trails, it is possible that these trails are influencing the establishment of species in the studied area.
\end{abstract}

Key words: Atlantic forest, conservation, multivariate analysis

RESUMO - (Padrões florísticos do componente arbóreo sob interferência de trilhas em um trecho de Floresta Ombrófila Densa de Transição em São Paulo, SP, Brasil). As trilhas podem alterar a composição florística de um determinado local, uma vez que em sua área de ocorrência algumas condições ambientais são visivelmente diferentes do interior da floresta. A hipótese central foi que as trilhas poderiam estar relacionadas a variações na composição de espécies, levando à formação de blocos florísticos, cada um formado por amostras sob mesmo nível de interferência. Foram instaladas 30 parcelas de $2 \times 50$ m na Reserva Biológica do Parque Estadual das Fontes do Ipiranga, São Paulo, SP, Brasil, sendo 10 adjacentes a uma trilha larga e de ampla utilização, $10 \mathrm{em}$ trilha de largura reduzida e pouco utilizada e 10 em área relativamente preservada. Foram amostrados todos os indivíduos arbóreos e as palmeiras com DAP $\geq 2,5 \mathrm{~cm}$. Análises de agrupamento (por UPGMA), ordenação (por CA e DCA) e TWINSPAN indicaram distinção florística entre os três setores. Como a composição florística variou conforme o nível de utilização e a largura das trilhas, é possível que estas estejam influenciando o estabelecimento de espécies no trecho estudado.

Palavras-chave: análises multivariadas, conservação, Floresta Atlântica

\section{Introdução}

O Brasil possui seis grandes domínios fitogeográficos em seu território (Ab'Saber 2003), cada um com suas peculiaridades de fauna, flora, solos, topografia, relevo, clima e histórico de ocupação (Joly et al. 1999). É notória a riqueza de formações florestais nesses domínios, as quais, a despeito de sua elevada diversidade, vêm experimentando o fenômeno preocupante da degradação ambiental oriunda de atividades antrópicas (Viana 1990, Joly et al. 1999). Duas das regiões fitoecológicas que exemplificam o problema são a Floresta Ombrófila Densa e a Floresta Estacional Semidecídua do Domínio Atlântico, as quais apresentam um histórico de perturbação relacionado à exploração desordenada dos recursos naturais (Valverde 1958, Kurtz \&

1. Com dados provenientes da Dissertação de Mestrado da primeira Autora pelo Programa de Pós-Graduação em Biodiversidade Vegetal e Meio Ambiente do Instituto de Botânica

2. Instituto de Botânica, Caixa Postal 3005, 01061-970 São Paulo, SP, Brasil

3. Universidade Estadual de Campinas, Programa de Pós-Graduação em Biologia Vegetal, Caixa Postal 6109, 13083-970 Campinas, SP, Brasil \& Universidade do Estado de Minas Gerais - Campus de Carangola, Faculdade de Filosofia, Ciências e Letras, 36800-000 Carangola, MG, Brasil

4. Autora para correspondência: julia.hirata@gmail.com 
Araújo 2000) e determinado por fracas políticas conservacionistas (Mori et al. 1981), estimulando o contínuo processo de fragmentação florestal.

Para que os processos ecológicos das nossas florestas sejam corretamente compreendidos, um passo importante é investigar padrões florísticos regionais e locais, inclusive em fragmentos florestais mais sujeitos a fontes potenciais de impacto. Com o amplo processo de fragmentação florestal decorrente da expansão desordenada das fronteiras agrícolas (Viana 1990), as florestas passaram a ter zonas de contato maiores com o meio circundante, favorecendo a exposição de parte da vegetação à insolação e aos ventos mais fortes (Alves Júnior et al. 2006). Os padrões de distribuição espacial, mortalidade e diversidade das espécies são frequentemente modificados com o efeito de borda (Rodrigues \& Nascimento 2006), devido em parte à redução na disponibilidade de água (Bierregaard et al. 1992).

Embora ainda faltem estudos, o conhecimento sobre o efeito de borda vem apresentando avanços claros. Por sua vez, os estudos sobre um efeito mais específico, o de trilhas abertas no interior das matas, encontram-se em posição mais negligenciada na pesquisa científica, embora essa fonte de impacto possa causar modificações importantes nas comunidades florestais (Cole 1978, Roovers et al. 2004). Roncero-Siles (2003) descreveu os impactos das trilhas sobre a vegetação como sendo i) diretos, pelo dano mecânico causado pela presença antrópica; e ii) indiretos, pelas mudanças nas propriedades físicas e químicas do solo, como o aumento da sua compactação. Em relação a isso, Kuss (1986) mencionou que alterações na intensidade de uso, drenagem do solo e microclima são os fatores que mais afetam o desenvolvimento e a fisiologia das plantas. Boucher et al. (1991) ressaltaram a baixa quantidade de estudos do impacto humano em trilhas, principalmente em florestas tropicais.

Dentre os poucos estudos feitos nesse sentido para a Mata Atlântica, foi verificado que um trecho de mata de São Paulo (o mesmo do presente estudo) e outro trecho em Viçosa-MG apresentaram algumas variações estruturais possivelmente relacionadas ao tipo de impacto causado por trilhas (Eisenlohr et al. 2009). Além de modificações na estrutura da vegetação nas bordas das trilhas, a luminosidade e a força dos ventos, potencialmente modificadas pela abertura da trilha, aliadas a impactos físicos por pisoteio (Roncero-Siles 2003, Roovers et al. 2004), podem resultar em uma ainda não mensurada alteração nos padrões florísticos em comunidades florestais atlânticas. Estudar trilhas com diferentes níveis de impacto antrópico poderá fornecer uma compreensão mais precisa dos padrões florísticos da floresta. Se forem encontradas variações associadas à trilha, o passo seguinte seria proceder à correta avaliação dos impactos do uso e formulação de planos de manejo que visem à manutenção das trilhas e preservação da floresta.

O objetivo do presente trabalho foi avaliar possíveis variações florísticas das comunidades arbóreas em três situações de interferências causadas por trilhas abertas em uma mata do município de São Paulo, de forma a responder à pergunta: é possível que trilhas estejam associadas ao estabelecimento de padrões florísticos locais?

A hipótese foi que haveria formação de blocos florísticos distintos associados ao nível de perturbação imposto pela trilha, isto é, as unidades amostrais seriam mais agrupadas e possuiriam maior afinidade florística quanto mais semelhantes fossem suas condições frente ao efeito potencial das trilhas.

\section{Material e métodos}

Área de estudo - O Parque Estadual das Fontes do Ipiranga (PEFI) localiza-se na região sul da cidade de

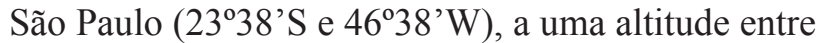
770 e $825 \mathrm{~m}$, ocupando área total de 526,38 ha, sendo 357 ha de Reserva Biológica (Melhem et al. 1981). Segundo o sistema de Köeppen, o clima do PEFI é do tipo Cwb. O solo é do tipo Latossolo VermelhoAmarelo (Embrapa Solos 2006), relativamente pobre em nutrientes. Em razão da proximidade geográfica de municípios que apresentam intensa industrialização, como Diadema e São Bernardo do Campo, o PEFI é uma Unidade de Conservação fortemente impactada por poluentes atmosféricos (Struffaldi-De Vuono et al. 1984).

A região metropolitana de São Paulo apresenta controvérsias quanto à sua classificação vegetacional no sistema do IBGE (Catharino et al. 2006). Enquanto Pivello \& Peccinini (2002) definiram a existência de Florestas Estacionais Semidecíduas para a cobertura vegetal da Grande São Paulo, Gomes \& Mantovani (2001) consideraram tais florestas como constituindo área de transição entre Floresta Estacional e Floresta Ombrófila Densa. No presente estudo, optou-se por classificar o PEFI como Floresta Ombrófila Densa de Transição, compondo parte da Floresta Atlântica sensu lato (Oliveira Filho \& Fontes 2000). 
Amostragem - Foram instaladas 30 parcelas de $2 \times$ $50 \mathrm{~m}$, sendo 10 em cada um dos setores em estudo (figura 1): 1) Setor Terra Batida - trilha com largura variando de 1,7 a 4,0 m e com $1.045 \mathrm{~m}$ de extensão. Sua classificação de uso é intensa, existindo registros de sua utilização desde a década de 1930 (Hoehne et al. 1941). Vem sendo utilizada amplamente por visitantes e caminhantes do Jardim Botânico, e sua manutenção é realizada por meio de limpeza manual e mecânica, esta última realizada com uso de trator. 2) Setor Fontes do Ipiranga - trilha histórica (Teixeira 1988) que, na época da amostragem (20042005), era pouco larga (variando de 0,6 a $1,0 \mathrm{~m}$ ) e apresentava uso reduzido. Foi fechada ao uso público na década de 1980, passando a ser usada somente pela fiscalização. Hoje se encontra suspensa em madeira ao longo de $360 \mathrm{~m}$ de extensão e largura constante de 1,5 m (exceto nas áreas de repouso), estando aberta ao público. 3) Setor Controle - área no interior da floresta, distante pelo menos $60 \mathrm{~m}$ de toda e qualquer fonte de perturbação antrópica direta (trilhas, estradas e muros). Nesses três setores, as condições de relevo e topografia são aparentemente similares.

Mediante a técnica de amostragem sistemática, cada parcela foi instalada paralelamente à respectiva trilha de referência, distante $7 \mathrm{~m}$ desta, utilizando-se fio de plástico e canos de PVC de modo a demarcála de maneira permanente, objetivando a realização de futuros estudos de dinâmica e de demografia de árvores, além de servir como instrumento didático ao público visitante e aos alunos do Instituto de Botânica. $\mathrm{O}$ intervalo entre parcelas vizinhas foi de $7 \mathrm{~m}$. Todos os indivíduos vivos com diâmetro a 1,30 $\mathrm{m}$ de altura do solo (DAP) igual ou superior a $2,5 \mathrm{~cm}$ (árvores e palmeiras) foram identificados com placas de alumínio numeradas.

As técnicas de coleta e processamento do material botânico seguiram as recomendações de Fidalgo \& Bononi (1984) e todos os indivíduos amostrados tiveram material botânico coletado, fértil ou estéril. As coletas estenderam-se durante dois anos para que se tivesse coleta fértil da maior parte dos indivíduos amostrados. A identificação do material botânico foi realizada com base nas monografias da Flora Fanerogâmica do Parque Estadual das Fontes do Ipiranga, por comparação com material botânico depositado no Herbário SP e por consulta a pesquisadores do Instituto de Botânica. A grafia dos binômios, incluindo suas respectivas autoridades, foi confirmada no banco de dados on line "Trópicos", do Missouri Botanical Garden (Mobot 2007), e as famílias foram classificadas seguindo-se a proposta do APG II (2003).

Preparo das matrizes - Com os dados de campo, foram produzidas duas matrizes florísticas: uma binária (presença ou ausência de cada espécie em cada parcela) e outra de abundância (número de indivíduos de cada espécie em cada parcela). Cada uma delas continha, inicialmente, 30 linhas (correspondendo às parcelas, os objetos da matriz) e 115 colunas (sendo este o número de espécies, os descritores da matriz). Em seguida, procedeu-se à análise de valores extremos (outliers) no PC-ORD versão 4.0 (McCune \& Mefford 1999), ao nível de corte 2.0, de forma a identificar e excluir amostras díspares das demais e que por isso poderiam afetar os dados (McCune \& Mefford 1999 - manual). As três parcelas (uma do setor Terra Batida e duas do setor Fontes do Ipiranga) identificadas como outliers na matriz binária foram as mesmas detectadas para a matriz de abundância.

Análise de Agrupamento Aglomerativa - A matriz de presença e ausência foi exportada para o software PAST versão 1.79 (Hammer et al. 2001), onde foi processada e gerou um dendrograma de similaridade florística por meio do método Média Aritmética não-ponderada (UPGMA), usando-se o índice de Dice-Sørensen. Foi calculado o coeficiente de correlação cofenética, que estabelece o nível de correlação entre a matriz de similaridade original e a matriz calculada (cofenética) durante o processo de montagem do dendrograma. Valores baixos (alguns pesquisadores sugerem $<0,7$, mas não há consenso) desse coeficiente implicam em alto nível de distorção do dendrograma em relação à similaridade real entre cada par de amostras (parcelas). Buscando comprovar a significância dos grupos formados, foi efetuada a análise não-paramétrica ANOSIM (Clarke 1993) também no PAST v.1.79, com 10.000 permutações. Esperava-se que cada setor (Controle, Fontes do Ipiranga e Terra Batida) formasse um agrupamento coeso, com alta similaridade entre suas parcelas constituintes e significativa dissimilaridade em relação às parcelas dos outros setores.

Ordenação - Se o objetivo do pesquisador for visualizar a afinidade das espécies amostradas em relação às áreas amostradas em um só gráfico (dito biplot), dois métodos principais de ordenação são possíveis: a PCA - Análise de Componentes Principais e a CA - Análise de Correspondência. Como a PCA assume que a variação das espécies ao longo do gradiente tenha comportamento monotônico (ver Hair et al. 2006 para pressupostos das análises 


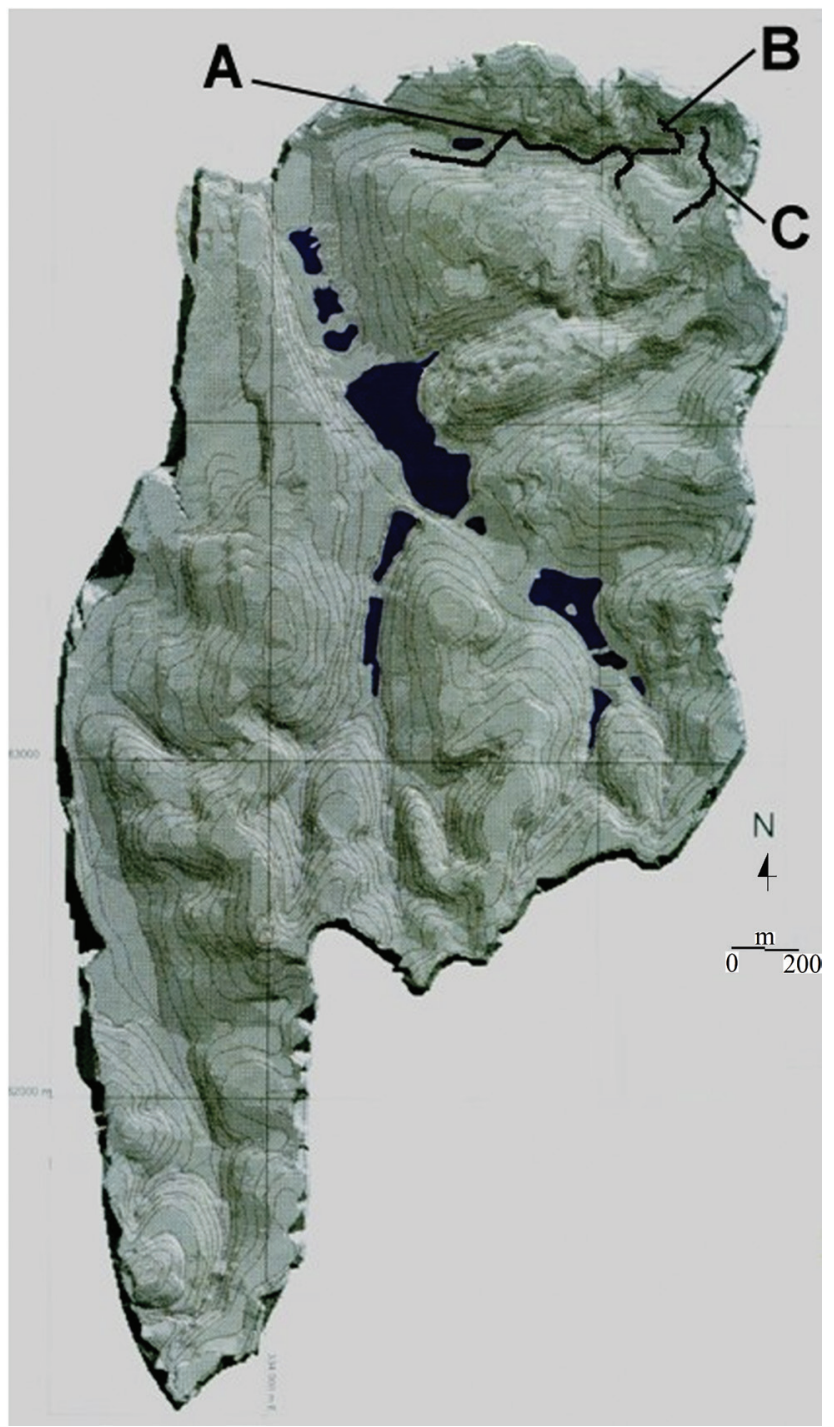

Figura 1. Localização das trilhas estudadas na Reserva Biológica do Parque Estadual das Fontes do Ipiranga, São Paulo, SP, Brasil. A - trilha do setor Terra Batida; B - trilha do setor Fontes do Ipiranga; $\mathrm{C}$ - trilha do setor Controle.

Figure 1. Site of the trails studied in the Biological Reserve of the Parque Estadual das Fontes do Ipiranga, Sao Paulo, SP, Brazil. A - Terra Batida sector trail; B - Fontes do Ipiranga sector trail; C - Control sector trail.

multivariadas e Palmer 2009 para escolha do método de ordenação mais apropriado), o que não ocorria no presente caso, optou-se por usar a CA para ordenar as parcelas a partir da matriz florística de abundância.

Analisar um gráfico biplot contendo muitas espécies (115, no presente caso) pode ser muito dispendioso de tempo e esforço e introduzir ruídos nas análises, sem haver essa necessidade, uma vez que algumas espécies (as menos abundantes) tendem a contribuir muito pouco para os padrões gerados pelas análises de ordenação (Gauch 1982). Pensando nisso, foram excluídas as espécies representadas por menos de cinco indivíduos na amostragem total, resultando em uma nova matriz contendo 25 espécies, do total de 115 da matriz original. Foi verificado se os padrões florísticos variariam entre as duas matrizes (completa e reduzida - na qual foram excluídas as espécies menos abundantes). Como não houve muita variação, os resultados obtidos com a matriz reduzida foram mantidos na análise final e na apresentação dos resultados.

A CA, em alguns casos, pode induzir a interpretações equivocadas com relação ao sentido do "gradiente" analisado e à afinidade entre as amostras, em razão da formação do "efeito de arco", comumente encontrado em maior ou menor grau. Assim, para que se tivesse maior segurança na análise de ordenação, também foi efetuada a DCA - Análise de Correspondência Distendida, que remove possíveis arcos. Esses dois métodos foram processados no PCORD versão 4.0 (McCune \& Mefford 1999).

Esperava-se, de acordo com a hipótese formulada, que fossem formados três blocos ao longo de cada gráfico de ordenação, com cada bloco sendo formado por parcelas do mesmo setor (Controle, Fontes do Ipiranga e Terra Batida).

TWINSPAN - Foi efetuada a análise de classificação divisiva TWINSPAN - Two-Way Indicator Species Analysis no PC-ORD v. 4.0 (McCune \& Mefford 1999), a partir da matriz binária, objetivando promover sucessivas dicotomizações hierárquicas para as parcelas (Gauch 1982) e obter uma classificação que pudesse auxiliar no entendimento das afinidades florísticas nas diferentes condições ecológicas oriundas do grau de interferência das trilhas. Divisões com autovalores superiores a 0,3 foram consideradas satisfatórias e passíveis de interpretação ecológica (Felfili \& Rezende 2003). Se a hipótese de formação de blocos florísticos fosse verdadeira, a primeira divisão da TWINSPAN provavelmente já mostraria uma dicotomia entre as parcelas do interior da floresta (setor Controle) e as parcelas sob interferência da trilha (setores Fontes do Ipiranga e Terra Batida), ou entre as parcelas do setor Terra Batida (o de maior impacto potencial) e os outros dois.

Ao final, foi feita uma comparação entre os resultados obtidos por esses métodos quanto às distinções florísticas evidenciadas para os três setores amostrados. 
Tabela 1. Listagem florística dos três setores amostrados no Parque Estadual das Fontes do Ipiranga, São Paulo, SP, Brasil, com o número de indivíduos.

Table 1. Floristic check-list of the three sectors surveyed in the Parque Estadual das Fontes do Ipiranga, Sao Paulo, Sao Paulo State, Brazil, including the number of individuals.

\begin{tabular}{|c|c|c|c|}
\hline Família/Espécie & Controle & Fontes do Ipiranga & Terra Batida \\
\hline \multicolumn{4}{|l|}{ Anacardiaceae } \\
\hline Tapirira guianensis Aubl. & 0 & 2 & 0 \\
\hline \multicolumn{4}{|l|}{ Annonaceae } \\
\hline Duguetia lanceolata A. St.-Hil. & 0 & 4 & 0 \\
\hline Guatteria australis A. St.-Hil. & 0 & 4 & 1 \\
\hline Rollinia sericea (R.E. Fries) R.E. Fries & 0 & 5 & 0 \\
\hline \multicolumn{4}{|l|}{ Araliaceae } \\
\hline Schefflera angustissima (Marchal) Frodin & 0 & 0 & 1 \\
\hline \multicolumn{4}{|l|}{ Arecaceae } \\
\hline Archontophoenix cunninghamiana H.Wendl.\& Drude & 0 & 18 & 26 \\
\hline Bactris setosa Mart. & 1 & 5 & 1 \\
\hline Euterpe edulis Mart. & 9 & 20 & 12 \\
\hline Euterpe oleracea Mart. & 0 & 2 & 0 \\
\hline Geonoma schottiana Mart. & 6 & 8 & 2 \\
\hline Syagrus romanzoffiana (Cham.) Glassm. & 9 & 15 & 16 \\
\hline \multicolumn{4}{|l|}{ Asteraceae } \\
\hline Piptocarpha macropoda (DC.) Baker & 0 & 4 & 0 \\
\hline \multicolumn{4}{|l|}{ Boraginaceae } \\
\hline Cordia ecalyculata Vell. & 4 & 5 & 0 \\
\hline Cordia sellowiana Cham. & 4 & 8 & 6 \\
\hline \multicolumn{4}{|l|}{ Burseraceae } \\
\hline Protium widgrenii Engl. & 1 & 0 & 1 \\
\hline \multicolumn{4}{|l|}{ Caricaceae } \\
\hline Jacaratia heptaphylla (Vell.) DC. & 0 & 1 & 10 \\
\hline \multicolumn{4}{|l|}{ Celastraceae } \\
\hline Maytenus robusta Reiss. & 5 & 0 & 0 \\
\hline \multicolumn{4}{|l|}{ Chrysobalanaceae } \\
\hline Licania hoehnii Pilger & 1 & 0 & 0 \\
\hline Licania kunthiana Hook f. & 1 & 0 & 0 \\
\hline \multicolumn{4}{|l|}{ Cyatheaceae } \\
\hline Cyathea delgadii Sternb. & 2 & 11 & 0 \\
\hline \multicolumn{4}{|l|}{ Elaeocarpaceae } \\
\hline Sloanea guianensis (Aubl.) Benth. & 6 & 0 & 0 \\
\hline Sloanea monosperma Vell. & 1 & 0 & 0 \\
\hline \multicolumn{4}{|l|}{ Euphobiaceae } \\
\hline Actinostemon klotzskii Pax & 22 & 0 & 0 \\
\hline Alchornea glandulosa Poepp. & 0 & 4 & 0 \\
\hline Alchornea sidifolia Müll. Arg. & 4 & 9 & 2 \\
\hline Alchornea triplinervea (Spreng.) Müll. Arg. & 4 & 0 & 3 \\
\hline Gonatogyne brasiliensis Müll. Arg. & 0 & 0 & 2 \\
\hline Pera glabrata (Schott) Baill. & 5 & 5 & 1 \\
\hline \multicolumn{4}{|l|}{ Lacistemaceae } \\
\hline Lacistema lucidum Schnizl. & 0 & 8 & 0 \\
\hline \multicolumn{4}{|l|}{ Lauraceae } \\
\hline Cinnamomum stenophyllum (Meisn.) Vatt. & 1 & 0 & 0 \\
\hline Endlicheria paniculata (Spreng.) Macbr. & 0 & 0 & 1 \\
\hline Nectandra grandiflora Ness \& Mart. ex Nees & 8 & 8 & 2 \\
\hline Nectandra lanceolata Nees \& Mart. ex Nees & 0 & 0 & 1 \\
\hline Nectandra megapotamica (Spreng.) Mez & 2 & 0 & 1 \\
\hline Nectandra oppositifolia Nees \& Mart. & 3 & 0 & 2 \\
\hline Ocotea aciphylla (Nees) Mez & 1 & 0 & 1 \\
\hline Ocotea diospyrifolia (Meisn.) Mez & 0 & 0 & 2 \\
\hline Ocotea elegans Mez & 3 & 5 & 1 \\
\hline Ocotea lanata (Nees) Mez & 0 & 1 & 1 \\
\hline Ocotea laxa (Ness) Mez & 6 & 0 & 2 \\
\hline Ocotea odorifera (Vell.) Rohwer & 2 & 0 & 0 \\
\hline Persea pyrifolia Nees \& Mart. ex. Nees & 0 & 0 & 2 \\
\hline Persea venosa Nees \& Mart. ex Nees & 1 & 5 & 1 \\
\hline Phoebe stenophylla $\mathrm{Mez}$ & 6 & 0 & 0 \\
\hline
\end{tabular}


Lecythidaceae

Cariniana estrellensis (Raddi) O. Ktze.

Leguminosae

Andira anthelmia (Vell.) Macbr.

Cassia ferruginea (Schrad.) Schrad. ex DC.

Copaifera langsdorffii Desf.

Dalbergia brasiliensis Vog.

Dalbergia frutescens (Vell.) Britton

Hymenaea courbaril L.

Machaerium angustifolium Vog.

Machaerium brasiliensis Vog.

Machaerium nictitans (Vell.) Benth.

Machaerium villosum Vog.

Piptadenia gonoacantha (Mart.) Macbr.

Sclerolobium denudatum Vog.

Senna macranthera (Collad.) Irwin \& Barneby

Senna multijuga (Rich.) Irwin \& Barneby

Melastomataceae

Miconia cabucu Hoehne

Miconia latecrenata (DC.) Naudin

Mouriri chamissoana Cogn.

Malvaceae

Luehea grandiflora Mart.

Meliaceae

Cabralea canjerana (Vell.) Mart.

Cedrela fissilis Vell.

Guarea macrophylla Vahl.

Trichilia catigua A. Juss.

\section{0}

Monimiaceae

Mollinedia elegans Tul.

\section{Moraceae}

Ficus enormis (Mart. \& Miq.) Miq.

Sorocea bonplandii (Baill.) Burger, Lanjow \& Boer

Myrtaceae

Calyptranthes grandifolia Berg

Campomanesia guaviroba (DC.) Kiaersk.

Eugenia cerasiflora Miq.

Eugenia excelsa Berg

Eugenia pruinosa Legr.

Gomidesia affinis (Cambess.) Legr.

Myrcia dichrophylla Legr.

Myrcia floribunda Miq.

Myrcia macrocarpa DC.

Myrcia obtecta (Berg) Kiaersk.

Myrcia pubipetala Miq.

Myrcia rostrata DC.

Plinia glomerata (Berg) Amshoff.

Psidium cattleyanum Sabine

Nyctagenaceae

Guapira opposita (Vell.) Reitz

Ochnaceae

Ouratea parviflora (DC.) Baill.

Ouratea semiserrata (Mart. \& Nees) Engl.

Olacaceae

Heisteria silvianii Schwacke

Phytolaccaceae

Phytolacca thyrsiflora Fenzl ex J.A. Schmidt

Podocarpaceae

Podocarpus sellowii Klotzsch 0

Polygonaceae

Coccoloba crescentiaefolia Cham.

Coccoloba warmingii Meissner

Rubiaceae

Amaioua guianensis Aubl.

Amaioua intermedia Mart.

Faramea montevidensis (Cham. \& Schlecht.) DC.

Guettarda viburnoides Cham. \& Schlecht.
3

0

0

0

2

0

0

0

0

0

6

0

0

0

0

0

2 
Posoqueria acutifolia Mart. Psychotria cephalantha (Müll. Arg.) Standley

Psychotria nemorosa Gardner Psychotria sessilis (Vell.) Müll. Arg.

Rutaceae Rudgea jasminoides (Cham.) Müll. Arg.

Esenbeckia febrifuga (A. St.-Hil.) A. Juss. ex Mart.

Sapindaceae

Cupania emarginata Cambess. Cupania oblongifolia Cambess.

Cupania vernalis Cambess.

Matayba elaeagnoides Raldk.

Sapotaceae

Ecclinusa ramiflora Mart.

Pouteria laurifolia (Gomes) Radlk.

Salicaceae

Casearia sylvestris Sw.

Solanaceae

Solanum rufescens Sendt.

Solanum swartzianum Roem. \& Schult.

Ulmaceae

Trema micrantha (L.) Blume

Urticaceae

Cecropia hololeuca Miq.

Verbenaceae

Aegiphila sellowiana Cham.

Vitex polygama Cham.

\section{Resultados e Discussão}

Dados florísticos gerais - Foram amostradas 115 espécies, 79 gêneros e 36 famílias de indivíduos vivos (tabela 1). As famílias mais ricas foram Lauraceae (15 espécies), Leguminosae e Myrtaceae (14 cada), Rubiaceae (9) e Arecaceae e Euphorbiaceae (6 cada), descritas na literatura como bem representadas em Florestas Montanas ou Submontanas da costa Atlântica dos Estados de São Paulo e Rio de Janeiro (Tabarelli \& Mantovani 1999, Catharino et al. 2006). No setor Terra Batida, o de maior interferência potencial por trilha, foram amostradas 66 espécies distribuídas em 25 famílias. As famílias mais ricas foram Lauraceae (12 espécies), Leguminosae (9), Myrtaceae (8), Rubiaceae e Arecaceae (5 cada). O setor Fontes do Ipiranga, sujeito a pouca interferência pela trilha homônima, teve 56 espécies de 25 famílias amostradas. As famílias mais ricas foram Myrtaceae (6 espécies), Arecaceae (6), Leguminosae (5), Lauraceae e Rubiaceae (4 cada). Por fim, no setor Controle foram amostradas 62 espécies em 24 famílias. As famílias mais ricas foram Lauraceae (10 espécies), Myrtaceae (8), Rubiaceae (6), Euphorbiaceae e Arecaceae (4 cada). Maiores detalhes referentes aos resultados dessa amostragem podem ser encontrados em Hirata (2006) e Eisenlohr et al. (2009).

Análise de Agrupamento Aglomerativa - Analisando

\begin{tabular}{lll}
10 & 0 & 0 \\
1 & 8 & 3 \\
3 & 0 & 2 \\
3 & 0 & 0 \\
7 & 3 & 1 \\
3 & 0 & 0 \\
5 & 0 & 0 \\
3 & 5 & 3 \\
0 & 0 & 7 \\
0 & 6 & 0 \\
7 & 5 & 0 \\
5 & 6 & 2 \\
0 & 0 & 3 \\
0 & 2 & 0 \\
2 & 0 & 1 \\
3 & 0 & 0 \\
0 & 0 & 1 \\
0 & 6 & 0 \\
0 & 1 & \\
\hline
\end{tabular}

o dendrograma da figura 2, nota-se, ao nível de aproximadamente 0,15 na escala do coeficiente de Dice-Sørensen, a formação de um grupo (à esquerda) contendo as parcelas da Terra Batida (setor de maior impacto potencial) e apenas uma parcela (Font6) das Fontes do Ipiranga (impacto intermediário). O outro grupo (à direita) é formado pelo restante das parcelas. Neste segundo grupo, os dois conjuntos de parcelas a seguir agrupados estão também de acordo com o esperado pela hipótese de blocos florísticos: à esquerda, as parcelas das Fontes do Ipiranga se unem, o mesmo ocorrendo, à direita, com as parcelas do interior da floresta (Controle). Parece então haver maior afinidade entre uma área sob impacto intermediário (Fontes do Ipiranga) com uma área presumivelmente sem impacto de trilha (Controle) do que com área sob impacto mais forte (Terra Batida). Pelo menos nessa etapa das análises, se tivéssemos que dividir os três setores em dois grupos por similaridade florística, a Terra Batida ficaria isolada. Porém, a afinidade entre setores diferentes mostra-se nitidamente baixa em todos esses casos (menos de 0,2 de similaridade de Dice-Sørensen). Considerando todo o dendrograma, o único subgrupo com mais de $60 \%$ de similaridade de Dice-Sørensen foi o formado por Font8 e Font10. O coeficiente de correlação cofenética foi de 0,75 , indicando boa confiabilidade (baixa distorção) na geração do dendrograma a partir dos dados originais. 


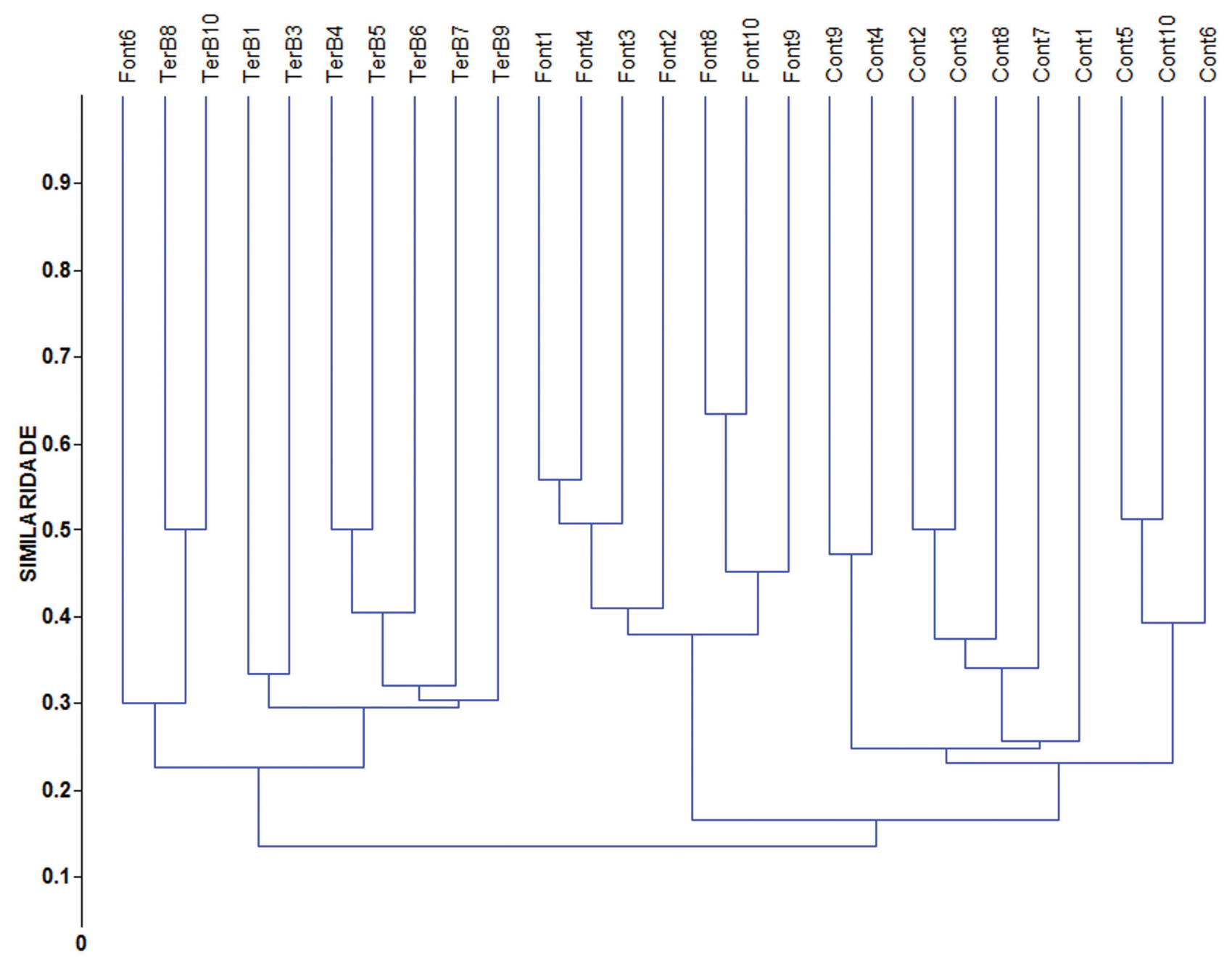

Figura 2. Dendrograma de Análise de Agrupamento (UPGMA, Dice-Sørensen) para as parcelas amostradas no Parque Estadual das Fontes do Ipiranga, São Paulo, SP, Brasil. TerB: parcelas do setor Terra Batida; Font: parcelas do setor Fontes do Ipiranga; Cont: parcelas do setor Controle. Coeficiente de correlação cofenética $=0,75$.

Figure 2. Dendrogram of Cluster Analysis (UPGMA, Dice-Sørensen) for the plots surveyed in the Parque Estadual das Fontes do Ipiranga, Sao Paulo, SP, Brazil. TerB: plots of Terra Batida sector; Font: plots of Fontes do Ipiranga sector; Cont: plots of Control sector. Cophenetic correlation coeficient $=0.75$.

De modo geral, portanto, foi possível notar a formação de três grandes grupos, cada qual formado quase que completamente por parcelas de um mesmo setor (Terra Batida $\times$ Fontes do Ipiranga $\times$ Controle). O teste ANOSIM indicou significativa dissimilaridade entre esses grupos $(\mathrm{p}<0,0001 ; \mathrm{R}=$ 0,711).

Amostras cujas espécies estão sujeitas a pressões seletivas comuns e com similaridades ecológicas (no nosso caso, parcelas próximas a trilhas, de um lado, e parcelas de interior de floresta, de outro) tendem a formar grupos florísticos coesos (Gauch 1982), mas a baixa similaridade geral entre as parcelas e entre os grupos indica que outras condições ambientais além das trilhas possam estar atuando na localidade. Variações nos teores de nutrientes dos solos ou aberturas repentinas de pequenas clareiras (Burslem \& Whitmore 1999), por exemplo, poderiam contribuir para a composição florística atual das parcelas, mas não foram mensuradas neste estudo. Nesse sentido, estudos futuros poderão se atentar a esses fatores e, se possível, quantificarem-nos, inclusive considerando a dinâmica do banco de plântulas, para que se possa atingir um quadro mais completo das variáveis 


\section{ANÁLISE DE CORRESPONDÊNCIA}

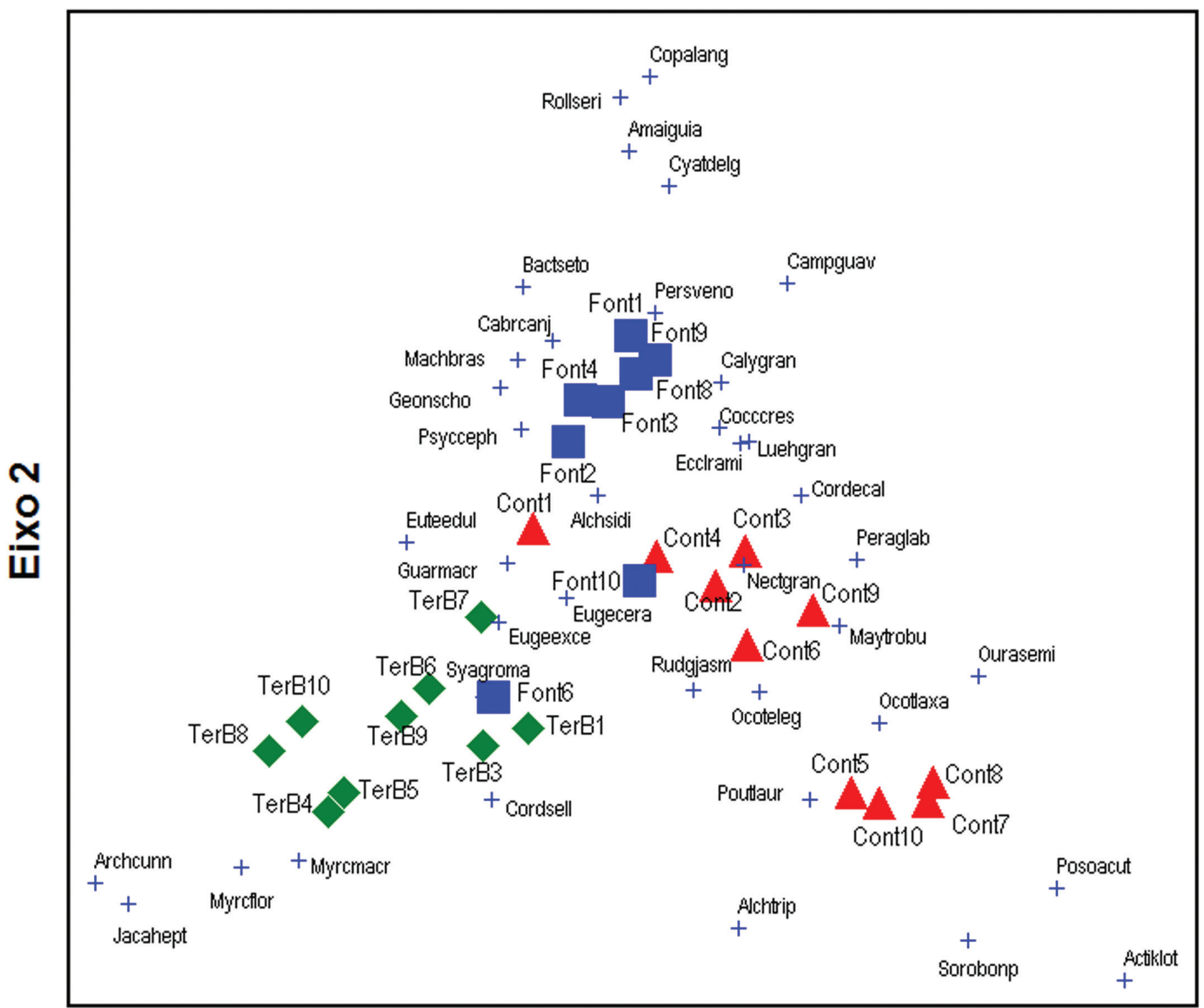

\section{Eixo 1}

Figura 3. Gráfico biplot resultante da ordenação por CA (Eixos 1 e 2) para a amostragem realizada no Parque Estadual das Fontes do Ipiranga, São Paulo, SP, Brasil. Losangos: parcelas do setor Terra Batida (TerB); Quadrados: parcelas do setor Fontes do Ipiranga (Font); Triângulos: parcelas do setor Controle (Cont). As espécies são codificadas pelas quatro primeiras letras do gênero seguidas das quatro primeiras letras do epíteto específico.

Figure 3. Biplot of CA ordination (Axes 1 and 2) for the sampling in the Parque Estadual das Fontes do Ipiranga, Sao Paulo, SP, Brazil. Diamonds: plots of the Terra Batida sector (TerB); Squares: plots of the Fontes do Ipiranga sector (Font); Triangles: plots of Control sector (Cont). The species are coded by the first four letters of the genus followed by first four letters of specific epithet.

ambientais presentes na amostragem. Dessa forma, seria possível investigar mais a fundo o quanto das variações florísticas poderia ser atribuído à trilha.

Ordenação - As análises por CA (figuras 3,4) e DCA (figura 5, 6) indicaram, no primeiro eixo, a formação de blocos florísticos razoavelmente nítidos nos setores Terra Batida e Controle, cada um constituído por parcelas do mesmo setor e, portanto, sob o mesmo grau de exposição ao fator trilha. Isso sugere que a trilha possa ter relação com os padrões florísticos locais, pois se parte da premissa de que outras variáveis, como relevo e topografia, estejam 


\section{ANÁLISE DE CORRESPONDÊNCIA}

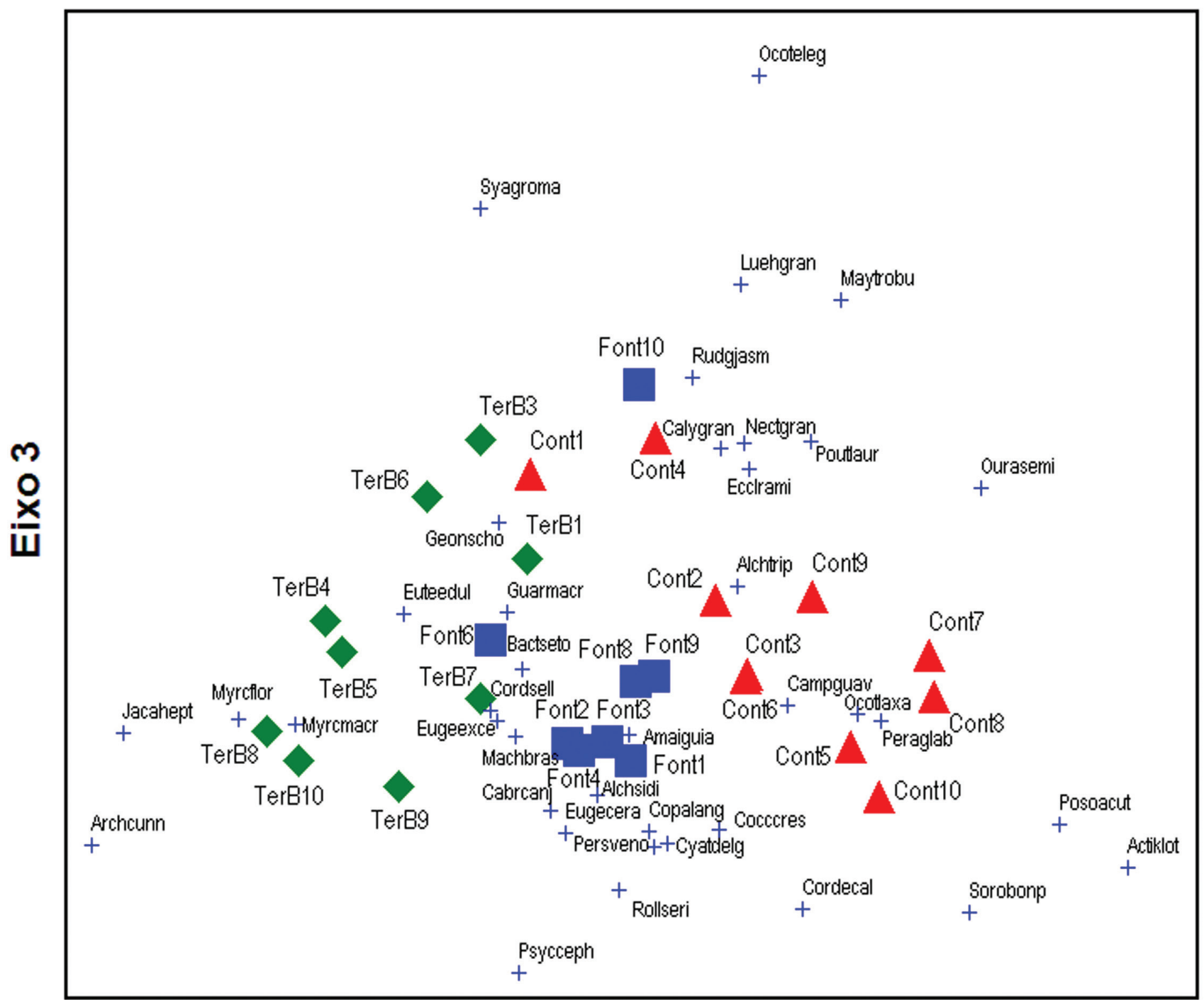

Eixo 1

Figura 4. Gráfico biplot resultante da ordenação por CA (Eixos 1 e 3) para a amostragem realizada no Parque Estadual das Fontes do Ipiranga, São Paulo, SP, Brasil. Losangos: parcelas do setor Terra Batida (TerB); Quadrados: parcelas do setor Fontes do Ipiranga (Font); Triângulos: parcelas do setor Controle (Cont). As espécies são codificadas pelas quatro primeiras letras do gênero seguidas das quatro primeiras letras do epíteto específico.

Figure 4. Biplot graph resulted of the ordination analysis by CA (Axes 1 and 3) for the sampling in the Parque Estadual das Fontes do Ipiranga, Sao Paulo, SP, Brazil. Diamonds: plots of the Terra Batida sector (TerB); Squares: plots of the Fontes do Ipiranga sector (Font); Triangles: plots of Control sector (Cont). The species are coded by the first four letters of the genus followed by first four letters of specific epithet.

minimamente controladas. Por outro lado, algumas parcelas, principalmente do setor Fontes do Ipiranga, parecem estabelecer uma transição entre os setores. $\mathrm{Na} \mathrm{CA}$, por exemplo, a parcela Font6 mostra-se ligada às parcelas da Terra Batida (como mostrado também no dendrograma da UPGMA), o mesmo ocorrendo com a parcela Font10 em relação às parcelas do setor Controle, e da Cont 1 em relação às parcelas dos outros dois setores (figura 3 ). O primeiro eixo da CA explicou apenas $10,23 \%$ e o da DCA, $15,02 \%$ da 


\section{ANÁLISE DE CORRESPONDÊNCIA DISTENDIDA}

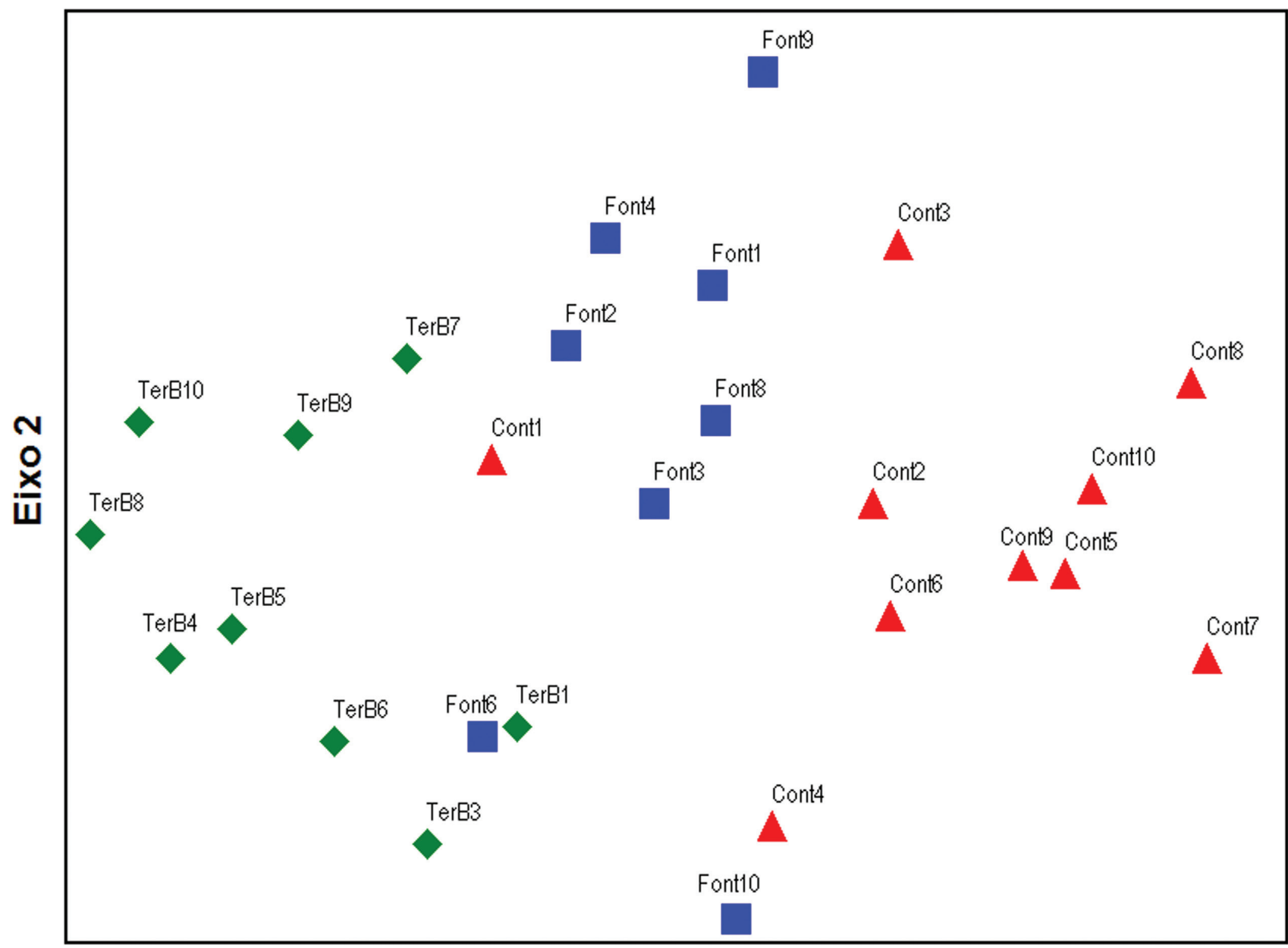

Eixo 1

Figura 5. Gráfico resultante da ordenação por DCA (Eixos 1 e 2) para a amostragem realizada no Parque Estadual das Fontes do Ipiranga, São Paulo, SP, Brasil. Losangos: parcelas do setor Terra Batida (TerB); Quadrados: parcelas do setor Fontes do Ipiranga (Font); Triângulos: parcelas do setor Controle (Cont).

Figure 5. Resultant graph of the ordination by DCA (Axes 1 and 2) for the sampling in the Parque Estadual das Fontes do Ipiranga, Sao Paulo, SP, Brazil. Diamonds: plots of the Terra Batida sector (TerB); Circles: plots of the Fontes do Ipiranga sector (Font); Triangles: plots of Control sector (Cont).

variância total nos dados ("inércia"), indicando que ainda haveria muita variância remanescente.

Observando-se o segundo e o terceiro eixos da CA (figuras 3 e 4, respectivamente) e da DCA (figuras 5 e 6 , respectivamente), a única diferença marcante entre os dois métodos é que o segundo eixo da CA mostra as parcelas das Fontes do Ipiranga mais acima das demais, em relação ao mesmo eixo da DCA, o que tem como consequência uma aparente mistura maior entre as parcelas no segundo eixo da DCA.
Essa diferença deve-se provavelmente a artefatos matemáticos utilizados na DCA, que tendem a "achatar" parte das amostras para remover possíveis arcos (um olhar atento à figura 3 mostra um arco discreto). Assim, no segundo eixo, a CA aponta para uma separação entre a maioria das parcelas do setor Fontes do Ipiranga em relação às demais parcelas. No terceiro eixo, tanto da CA quanto da DCA, a separação entre os setores já não é clara. Desse modo, nota-se que a distinção florística entre os setores foi 


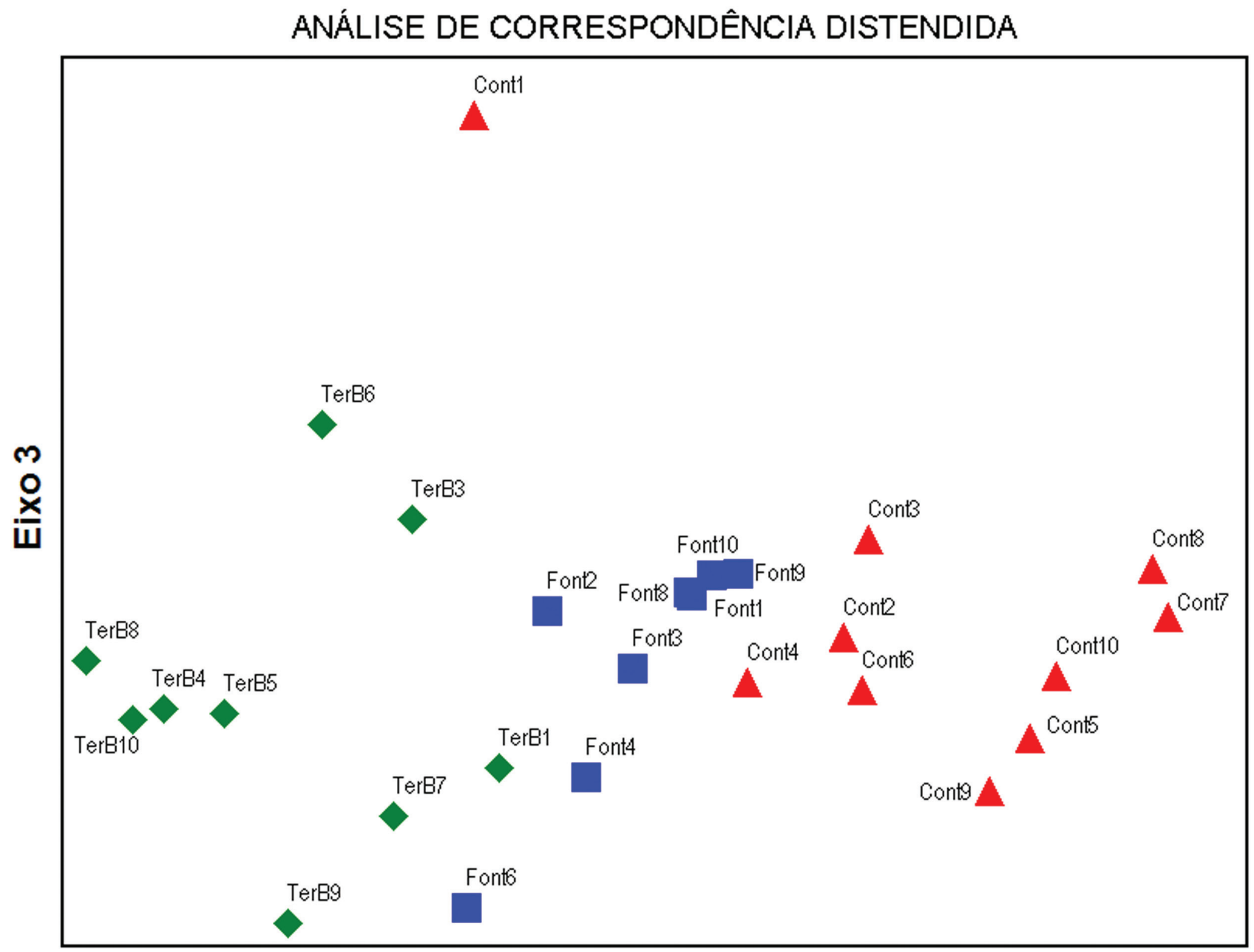

Eixo 1

Figura 6. Gráfico resultante da ordenação por DCA (Eixos 1 e 3) para a amostragem realizada no Parque Estadual das Fontes do Ipiranga, São Paulo, SP, Brasil. Losangos: parcelas do setor Terra Batida (TerB); Quadrados: parcelas do setor Fontes do Ipiranga (Font); Triângulos: parcelas do setor Controle (Cont).

Figure 6. Resultant graph of the ordination by DCA (Axes 1 and 3) for the sampling in the Parque Estadual das Fontes do Ipiranga, Sao Paulo, SP, Brazil. Diamonds: plots of the Terra Batida sector (TerB); Circles: plots of the Fontes do Ipiranga sector (Font); Triangles: plots of Control sector (Cont).

uma tendência marcante dos dois primeiros eixos (os que mais explicam sobre a variância total dos dados), mas além do efeito da trilha parece haver outros fatores não mensurados, dos quais alguns possivelmente estocásticos e espaciais, que também contribuiriam para a conformação dos dados e para a afinidade entre as parcelas. A explicação dos eixos 2 e 3 foi de $9,71 \%$ e $7,21 \%$, respectivamente, na CA, e de $7,33 \%$ e $4,85 \%$, respectivamente, na DCA.

Quanto à relação entre espécies e parcelas, o gráfico dos primeiros dois eixos da CA (figura 3) evidencia à esquerda a afinidade de Archontophoenix cunninghamii, Jacaratia heptaphylla, Myrcia floribunda, Myrcia macrocarpa e Cordia sellowiana por parcelas sob influência potencialmente maior do efeito de trilha (Terra Batida). Por sua vez, espécies como Actinostemon klotschi, Sorocea bonplandii, Ocotea laxa, Pouteria laurifolia e Posoqueria acutifolia apresentaram maior relação com as parcelas do interior da floresta (à direita). As demais espécies, tendo se situado na parte central do gráfico, parecem constituir uma flora intermediária. 


\section{TODAS AS PARCELAS}

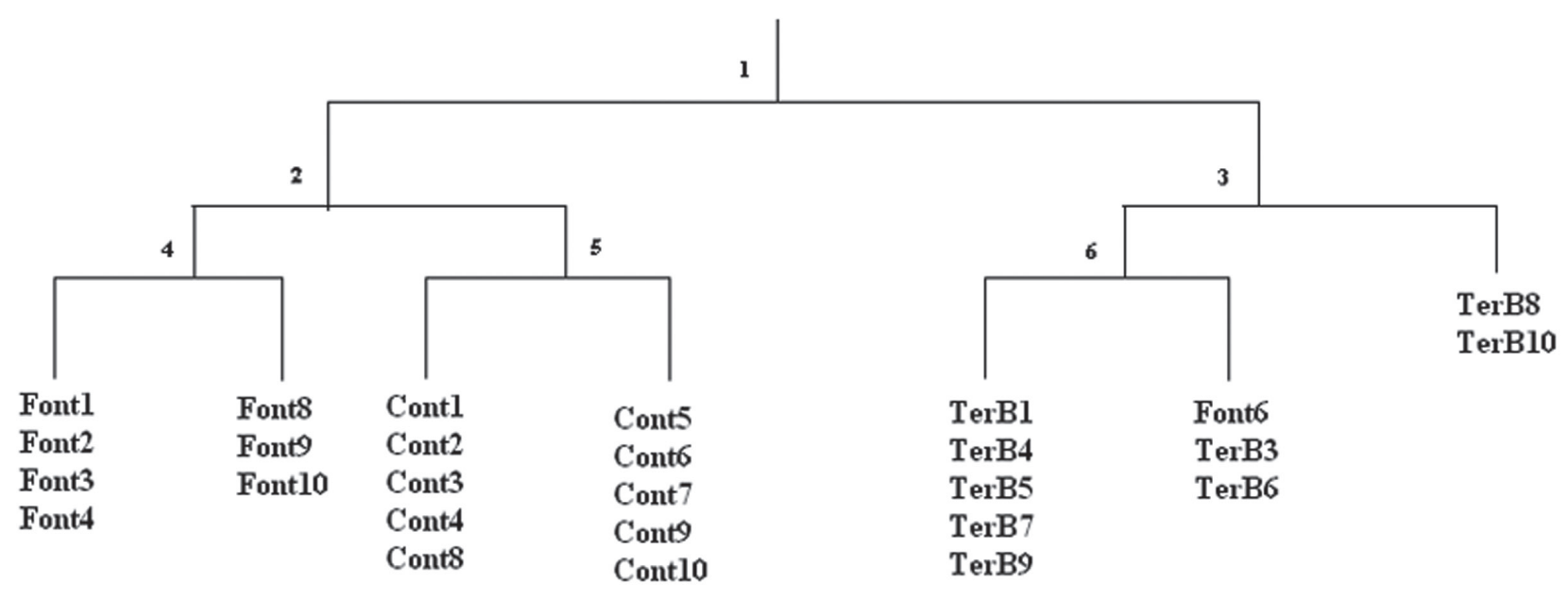

Figura 7. Análise TWINSPAN para as parcelas amostradas no Parque Estadual das Fontes do Ipiranga, São Paulo, SP, Brasil. TerB: parcelas do setor Terra Batida; Font: parcelas do setor Fontes do Ipiranga; Cont: parcelas do setor Controle.

Figure 7. TWINSPAN analysis for the plots surveyed in the Parque Estadual das Fontes do Ipiranga, Sao Paulo, SP, Brazil. TerB: plots of the Terra Batida sector; Font: plots of the Fontes do Ipiranga sector; Cont: plots of the Control sector.

Tabela 2. Comparação entre os resultados encontrados com uso de diferentes métodos, para investigação dos padrões florísticos em um trecho do Parque Estadual das Fontes do Ipiranga, São Paulo, SP, Brasil.

Table 2. Comparative table between the results found by different methods used in the investigation about the floristic patterns in a stretch of the Parque Estadual das Fontes do Ipiranga, Sao Paulo, Sao Paulo State, Brazil.

\begin{tabular}{|c|c|c|c|c|}
\hline & UPGMA & $\mathrm{CA}$ & DCA & TWINSPAN \\
\hline $\begin{array}{l}\text { Mistura entre parcelas } \\
\text { de diferentes setores }\end{array}$ & Pouca & $\begin{array}{l}\text { Pouca no } 1^{\circ} \text { e no } 2^{\circ} \\
\text { eixos e muita no } 3^{\circ}\end{array}$ & $\begin{array}{l}\text { Pouca no } 1^{\circ} \text { eixo, } \\
\text { razoável no } 2^{\circ} \text { eixo e } \\
\text { muita no } 3^{\circ}\end{array}$ & $\begin{array}{l}\text { Pouca. A partir da } 2^{\mathrm{a}} \\
\text { divisão, apenas um grupo } \\
\text { apresentou mistura }\end{array}$ \\
\hline $\begin{array}{l}\text { Formação de grupos/ } \\
\text { blocos nítidos de acordo } \\
\text { com o grau do efeito de } \\
\text { trilha, em alguma etapa }\end{array}$ & $\begin{array}{l}\text { Sim (confirmado no teste } \\
\text { ANOSIM) }\end{array}$ & $\begin{array}{l}\text { Sim, nos primeiros } \\
\text { dois eixos, mas } \\
\text { veja comentários no } \\
\text { texto }\end{array}$ & $\begin{array}{l}\text { Sim, no } 1^{\circ} \text { eixo, mas } \\
\text { veja comentários no } \\
\text { texto }\end{array}$ & Sim. \\
\hline
\end{tabular}

Parece então que as trilhas têm participado de fatores seletivos condicionando a abundância destas espécies. Por outro lado, a resposta de uma espécie às condições ambientais do meio pode depender de uma série de inter-relações bióticas (Harper 1977), o que torna extremamente difícil definir como cada espécie está respondendo ao fator trilha, ainda mais se considerando que são muitos os elementos integrantes desse tipo de interferência, tais como variação na luminosidade, temperatura, umidade do ar, entre outros. Assim, muitas espécies certamente apresentam respostas a alguns desses elementos, mas não a outros, o que resulta num comportamento intrigante dessas espécies nesse tipo de análise. Esse seria o caso, por exemplo, de Eugenia cerasiflora (centro do gráfico), que apresenta afinidade com parcelas em diferentes condições de efeito de trilha. TWINSPAN - A análise TWINSPAN (figura 7) indicou, em sua primeira divisão (autovalor = 0,4837), forte separação entre as parcelas do setor Terra Batida (à direita) e as demais parcelas; somente Font6 não se juntou ao grupo da esquerda, seguindo 
a tendência apresentada nas análises anteriores. É possível que essa parcela, embora não detectada na análise de outliers, esteja enfrentando situações ambientais peculiares não observadas durante a amostragem, como por exemplo a abertura de clareiras (não mensurada) antes do levantamento, que poderiam ser determinantes para os resultados florísticos encontrados (Denslow 1987). Nas divisões seguintes da TWINSPAN, observa-se claramente que há permanência, no mesmo grupo, de parcelas sob efeito similar das trilhas, corroborando as análises de ordenação e de agrupamento. Todas as divisões da TWINSPAN apresentaram autovalores acima de 0,3.

Uma comparação entre os resultados encontrados nos diferentes métodos empregados é apresentada na tabela 2. Em comum, os resultados encontrados indicam uma possível participação das trilhas nos padrões florísticos do trecho estudado do Parque Estadual das Fontes do Ipiranga, uma vez que todos os métodos apontaram para a formação de grupos nítidos de acordo com o grau de interferência da trilha. Contudo, alguns resultados indicaram mistura entre parcelas de diferentes setores, o que sugere que outros fatores também influenciaram a composição florística no trecho estudado.

Estando claras as diferenças florísticas do componente arbóreo entre os setores amostrados no Parque Estadual Fontes do Ipiranga, parece que o próximo passo é compreender como outras formas de vida, como as lianas e as epífitas, respondem à presença e utilização de trilhas. Questões espaciais também devem ser investigadas, pois se trata de um componente importante na detecção de padrões florísticos. Além disso, outros fragmentos de Floresta Atlântica devem ser estudados de forma a verificar se os resultados aqui encontrados se repetem ou se são exclusivas de um fragmento extremamente perturbado por força do seu entorno antropizado.

\section{Agradecimentos}

A Maria Cláudia Medeiros, Luciano Moreira da Silva, Ana Carolina Laurenti dos Santos, Maria Francisca Roncero Siles, Sonia Aragaki, Marie Sugiyama, pela ajuda nos trabalhos de campo; aos taxonomistas do Herbário do Instituto de Botânica, pela ajuda nas identificações; a Clever Pinto, pelo auxílio na edição da figura 1; e aos dois revisores anônimos, pelas contribuições para a versão final.

\section{Literatura citada}

Ab'Saber, A.N. 2003. Os domínios de natureza no Brasil: potencialidades paisagísticas. Ateliê Editorial, São Paulo.

Alves Júnior, F.T., Brandão, C.F.L.S, Rocha, K.D., Marangon, L.C. \& Ferreira, R.L.C. 2006. Efeito de borda na estrutura de espécies arbóreas em um fragmento de Floresta Ombrófila Densa, Recife, PE. Revista Brasileira de Ciências Agrárias 1: 49-56.

APG II. 2003. An update of the Angiosperm Phylogeny Group classification for the orders and families of flowering plants: APG II. Botanical Journal of the Linnean Society 141: 399-436.

Bierregaard, R.O., Lovejoy, T. E., Kapos, V., Santos, A.A. \& Hutchings, R.W. 1992. The biological dynamics of tropical rainforest fragments. BioScience 42: 859-866.

Boucher, D.H., Aviles, J., Chepote, R., Gil, O.E.D. \& Vilchez, B. 1991. Recovery of trailside vegetation from trampling in a Tropical Rain Forest. Environmental Management 15:257-262.

Burslem, D.F.R.P. \& Whitmore, T.C. 1999. Species diversity, susceptibility to disturbance and tree population dynamics in tropical rain forest. Journal of Vegetation Science 10: 767-776.

Catharino, E.L.M., Bernacci, L.C., Franco, G.A.D.C., Durigan, G. \& Metzger, J.P. 2006. Aspectos da composição e diversidade do componente arbóreo das florestas da Reserva Florestal do Morro Grande, Cotia, SP. Biota Neotropica 6(2): www.biotaneotropica.org.br/ v6n2/pt/abstract?article+bn00306022006.

Clarke, K.R. 1993. Non-parametric multivariate analysis of changes in community structure. Australian Journal of Ecology 18: 117-143.

Cole, D.N. 1978. Estimating the susceptibility of wildland vegetation to trailside alteration. The Journal of Applied Ecology 15: 281-286.

Denslow, J.S. 1987. Tropical rainforest gaps and tree species diversity. Annual Review of Ecology and Systematics 18: 431-451.

Eisenlohr, P.V., Melo, M.M.R.F. \& Silva, A.V. 2009. Trilhas afetam comunidades arbóreas florestais? Dois levantamentos na Floresta Atlântica do sudeste brasileiro. Hoehnea 36: 293-302.

Embrapa Solos. 2006. Sistema Brasileiro de Classificação de Solos. 2 ed. Embrapa Solos, Rio de Janeiro. 
Felfili, J.M. \& Rezende, R.P. 2003. Conceitos e métodos em fitossociologia. Comunicações Técnicas Florestais 5 (1). Departamento de Engenharia Florestal, Universidade de Brasília, Brasília.

Fidalgo, O. \& Bononi, V.L.R. 1984. Técnicas de coleta, preservação e herborização de material botânico. Instituto de Botânica, São Paulo.

Gauch, H.G. 1982. Multivariate analysis in community ecology. Cambridge University Press, Cambridge.

Gomes, E.P.C. \& Mantovani, W. 2001. Size structure of six tree populations in a subtropical rain forest in southeastern Brazil. Naturalia 26: 131-158.

Hair, J.F., Anderson, R.E., Tatham, R.L. \& Black, W.C. 2006. Análise multivariada de dados. 5 ed. Bookman, Porto Alegre.

Hammer, Ø., Harper, D.A.T. \& Ryan, P.D. 2001. PAST: Paleontological Statistics package for education and data analysis. Paleontologia Electronica 4(1) (versão eletrônica).

Harper, J.L. 1977. Population Biology of Plants. Academic Press, London.

Hirata, J.K.R. 2006. Florística e estrutura do componente arbóreo de trilhas do Parque Estadual das Fontes do Ipiranga, São Paulo, SP. Dissertação de Mestrado, Instituto de Botânica, São Paulo.

Hoehne, F.C., Kuhlmann, M. \& Handro, O. 1941. O Jardim Botânico de São Paulo. Departamento de Botânica do Estado, São Paulo.

Joly, C.A., Aidar, M.P.M., Klink, C.A., McGrath, D.G., Moreira, A.G., Moutinho, P., Nepstad, D.C., Oliveira, A.A., Pott, A., Rodal, M.J.N. \& Sampaio, E.V.S.B. 1999. Evolution of the Brazilian phytogeography classification systems: implications for biodiversity conservation. Ciência e Cultura 51: 331-348.

Kurtz, B.C. \& Araújo, D.S.D. 2000. Composição florística e estrutura do componente arbóreo de um trecho de Mata Atlântica na Estação Ecológica Estadual do Paraíso, Cachoeiras de Macacu, Rio de Janeiro, Brasil. Rodriguésia 51: 69-112.

Kuss, F.R. 1986. A review of major factors influencing plant responses to recreation impacts. Environmental Management 10: 637-650.

McCune, B. \& Mefford, M.J. 1999. PC-ORD multivariate analysis of ecological data, v. 4.0. MjM Software Design, Gleneden Beach.
Melhem, T.S., Giulietti, A.M., Forero, E., Barroso, G.M., Silvestre, M.S.F., Jung, S.L., Makino, H., Melo, M.M.R.F., Chiea, S.C., Wanderley, M.G.L., Kirizawa, M. \& Muniz, C. 1981. Planejamento para a elaboração da "Flora Fanerogâmica da Reserva do Parque Estadual das Fontes do Ipiranga (São Paulo, Brasil)". Hoehnea 9: 63-74.

Mobot. 2007. Missouri Botanical Garden Plant Science. Database - W3 TRÓPICOS. Disponível em: $<$ http://www.mobot.org $>$ (acesso ao longo do ano de 2007).

Mori, S.A., Boom, B.M. \& Prance, G.T. 1981. Distribution patterns and conservation of eastern Brazilian coastal forest species. Brittonia 33: 233-245.

Oliveira-Filho, A.T. \& Fontes, M.A.L. 2000. Patterns of floristic differentiation among Atlantic Forests in southeastern Brazil and the influence of climate. Biotropica 32: 793-810.

Palmer, M. 2009. Ordination Web Page. Disponível em: $<$ http://ordination.okstate.edu/ $>$ (acesso em 08. 2009).

Pivello, V.R. \& Peccinini, A.A. 2002. A vegetação do PEFI. In: D.C. Bicudo, , M.R. Forti, \& C.E.M. Bicudo (orgs.). Parque Estadual das Fontes do Ipiranga (PEFI): unidade de conservação que resiste à urbanização. Secretaria de Estado do Meio Ambiente, São Paulo, pp. 75-92.

Rodrigues, P.J.F.P. \& Nascimento, M.T. 2006. Fragmentação florestal: breves considerações sobre efeito de borda. Rodriguésia 57: 63-74.

Roncero-Siles, M.F. 2003. Modelagem espacial para atividades de visitação pública em áreas naturais. Dissertação de Mestrado, Universidade de São Paulo, São Paulo.

Roovers, P., Baeten, S. \& Hermy, M. 2004. Plant species variation across path ecotones in a variety of common vegetation types. Plant Ecology 170: 107-119.

Struffaldi-De Vuono, Y., Lopes, M.I.M.S. \& Domingos, M. 1984. Poluição atmosférica e elementostóxicos na Reserva Biológica do Instituto de Botânica, São Paulo, Brasil. Revista Brasileira de Botânica 7: 149-156.

Tabarelli, M. \& Mantovani, W. 1999. A riqueza de espécies arbóreas na floresta atlântica de encosta no estado de São Paulo (Brasil). Revista Brasileira de Botânica 22: 217-223.

Teixeira, A.R. 1988. Resenha Histórica do Instituto de Botânica de São Paulo. Ciência e Cultura 40: 
1045-1054.

Valverde, O. 1958. Estudo regional da Zona da Mata de Minas Gerais. Revista Brasileira de Geografia 20: 1-82.

Viana, V.M. 1990. Biologia e manejo de fragmentos florestais. In: Anais do Congresso Florestal Brasileiro, 6, Campos do Jordão, 1990. Sociedade Brasileira de Silvicultura/Sociedade de Engenheiros Florestais, Curitiba, pp. 113118. 